\title{
The Societal Impact of Herpes Zoster and Postherpetic Neuralgia on Patients, Life Partners, and Children of Patients in Germany
}

\author{
Thomas Weinke, ${ }^{1}$ Andrea Glogger, ${ }^{2}$ Isabelle Bertrand, ${ }^{3}$ and Kati Lukas ${ }^{3}$ \\ ${ }^{1}$ Klinikum Ernst von Bergmann, Gastroenterology and Infectious Disease, Charlottenstr 72, 14467 Potsdam, Germany \\ ${ }^{2}$ GfK Healthcare, Nordwestring 101, 90419 Nurnberg, Germany \\ ${ }^{3}$ Sanofi Pasteur MSD, 162 Avenue Jean Jaurès, CS 50712, 69367 Lyon Cedex 07, France \\ Correspondence should be addressed to Kati Lukas; klukas@spmsd.com
}

Received 3 October 2014; Accepted 9 November 2014; Published 8 December 2014

Academic Editor: Joav Merrick

Copyright (C) 2014 Thomas Weinke et al. This is an open access article distributed under the Creative Commons Attribution License, which permits unrestricted use, distribution, and reproduction in any medium, provided the original work is properly cited.

\begin{abstract}
The aim of this study was to assess the impact of herpes zoster (HZ) and postherpetic neuralgia (PHN) on the daily activities of patients and family members who care for them. Some former patients and family members participated in face-to-face interviews or in a T-group meeting (qualitative phase) and some participated in telephone interviews (quantitative phase). They all expressed feelings of helplessness and frustration mixed with depression, sadness, or rage. Many of the former patients said their lives stopped, in contrast to family members who said that their lives were busy and stressful. Family members caring for patients with PHN were more psychologically stressed than those caring for patients with HZ. Although former patients appreciated the psychological and emotional support given by their family members, they underestimated the impact that their disease had on them. Former patients and their family never forgot this illness and its considerable impact on their lives, particularly when PHN occurred. We need to raise the awareness of the general public about the real life impact of $\mathrm{HZ}$ and PHN and their often severe, debilitating consequences and the potential benefits from vaccination.
\end{abstract}

\section{Introduction}

Herpes zoster (HZ) or shingles is the clinical manifestation of the reactivation of latent varicella zoster virus $(\mathrm{VZV})$ which can occur several decades after the initial infection with varicella virus (chickenpox) [1]. Most adults have had chickenpox, most of the time in their childhood; therefore, almost everyone is potentially at risk of developing HZ. Following the initial infection, the virus becomes latent in the nervous system and when the virus is reactivated, the individual develops HZ. HZ is generally characterised by a unilateral vesicular rash, often with acute pain [2]. The risk of VZV reactivation and, therefore, $\mathrm{HZ}$ increases with age. Even if the reasons are not completely understood, a decline in VZVspecific immunity, observed with natural immunosenescence that occurs with aging or immunosuppression secondary to certain diseases or immunosuppressant therapy, is known to favour symptomatic reactivation of VZV [2]. The clinical course of $\mathrm{HZ}$ can involve major complications, such as postherpetic neuralgia (PHN) which is a frequent, debilitating complication [3]. Although there is no consensus on the standard definition for PHN, it is often defined as pain that persists for $\geq 3$ months after the onset of the HZ rash [4]. There are no factors that can predict who will develop HZ or how severe the disease will be. In this setting of unpredictability of the disease and its severe consequences, prevention is important. Currently, there are no preventative drug treatments for $\mathrm{HZ}$ or $\mathrm{PHN}$, and although some treatments are available, pain control is often difficult and unsatisfactory. In this setting, the aim of HZ treatment is to limit viral replication at an early stage of the disease and to relieve pain but it cannot prevent the onset of PHN. There is an unmet medical need [5]. The only effective prevention strategy is vaccination.

Increasingly, the importance of quality of life (QoL) and other patient-reported outcomes has been recognised in many disease areas, particularly in the absence of clinical 
data. Several observational studies have reported the significant impact that $\mathrm{HZ}$ and $\mathrm{PHN}$ can have on the patients' QoL and their daily activities [6-10]. These conditions can also have a deleterious effect on the patients' functional ability, even resulting in patients becoming housebound or inactive, with a greater impact on those who develop PHN [10-12]. While many studies have assessed the impact of $\mathrm{HZ}$ and PHN on the QoL and daily activities of patients, to our knowledge none have assessed the broader societal impact of the disease on the relatives of patients with $\mathrm{HZ}$ or PHN. The real impact of $\mathrm{HZ}$ and $\mathrm{PHN}$ remains largely underestimated. This was illustrated in one study that included patients with and without HZ (recruited through general practitioners) and controls from the general public. The results showed that although the controls were aware of $\mathrm{HZ}$ and its associated pain, the level of knowledge of patients with $\mathrm{HZ}$ was higher [13]. This shows that there is a need to increase awareness.

The aim of our study was to assess and quantify the societal impact of $\mathrm{HZ}$ and PHN on patients and their family members (life partners or children) who were involved in caring for the patient using qualitative and quantitative methods and patient-reported outcome tools.

\section{Methods}

The study was designed with two phases: a qualitative and a quantitative phase using specifically designed questionnaires developed by a multidisciplinary team. More detailed information on the study design is available on request from the authors. The aim of the qualitative phase was to evaluate in detail the overall societal impact of $\mathrm{HZ} / \mathrm{PHN}$ and its burden on patients and their relatives. The information gathered was used to formulate hypotheses that were tested in the quantitative phase.

The study was performed in subjects who had suffered from $\mathrm{HZ}$ or PHN during the previous five years. The patient was classified as $\mathrm{HZ}$ if the $\mathrm{HZ}$-associated pain lasted $<3$ months after rash onset and as $\mathrm{PHN}$ if the HZ-associated pain lasted $\geq 3$ months after rash onset. Both patients and family members were recruited through physicians (mainly general practitioners) to ensure that the patients had been correctly diagnosed with $\mathrm{HZ}$ or PHN by a physician.

2.1. Qualitative Phase. The subjects were invited to participate in either an in-depth face-to-face interview or a therapeutic group (T-group) interview. A psychologist conducted the T-group interview and together with a social scientist conducted the individual face-to-face interviews in a studio setting with a video recording that was later analysed. Both the psychologist and the social scientist were employees of GfK Healthcare who were contracted to conduct the study.

2.1.1. Face-to-Face In-Depth Interviews. The screening criteria for the former HZ/PHN patients included age (50-59, $\geq 60$ years), patients who had suffered from $\mathrm{HZ} / \mathrm{PHN}$ in the previous five years, those who were aged $\geq 50$ years when they suffered from HZ/PHN, and those who had consulted a physician because of their shingles. The former patients had had to have pain associated with the shingles. The screening criteria for the family members of former patients were that the former patient had to be aged $\geq 50$ years, the life partners had to be aged $\geq 50$ years, and children of former patients had to be aged between 20 and 49 years.

There were 12 face-to-face in-depth interviews conducted in Düsseldorf and Frankfurt, which lasted for 75 minutes with

(i) three former patients who suffered from $\mathrm{HZ}$;

(ii) three former patients who suffered from $\mathrm{PHN}$;

(iii) three life partners of former patients;

(iv) three children of former patients who lived close to their parent.

The areas covered during these interviews were

(i) their rational and emotional perception of $\mathrm{HZ}$ or PHN;

(ii) the emotional and rational challenges of their life with $\mathrm{HZ}$ or PHN or of living with a patient;

(iii) detailed assessment of the acute versus chronic stages: particularly for the impact on their close and more distant social environment; functional impact including routine daily activities such as work or housework and other physical activities; expenses incurred, in addition to those reimbursed by their health insurance; psychological impact;

(iv) summary of their experience with $\mathrm{HZ}$ or PHN and their outlook for the future.

2.1.2. Therapeutic Group (T-Group). The so-called T-group methodology was originally developed in psychology [14]. Since then it has been used very successfully in qualitative market research (Figure 1). The T-group methodology allows two different target groups, in our case, former patients and family members that are usually not brought together, to be questioned at the same time. Although homogeneous groups have greater cohesion, heterogeneity and diversity within a group can be an asset as this provides the participants with multiple knowledge bases and different perspectives to help the group members to understand others points of view. Thus, it is critical that group cohesion be a focus of heterogeneous groups so that the multiple perspectives are respected and supported [15-17].

Homogeneity is present within the subgroups and heterogeneity between the two target groups. The openness of the patients and family members is strengthened through the group setting as they feel accepted and understood in their subgroups and are backed-up by their peers. In contrast with a standard group setting, it is even more important to establish an atmosphere of trust, warmth, and empathy as well as understanding and acceptance. In this context, the homogeneity of the subgroups is motivational and contributes to the group cohesion which is essential to maximize the output, particularly given the time constraints.

In contrast to long-term group therapy, the patients and family members who participated in this short-term study design were not related. If they had been related, the shortterm setting would not allow enough time and space to 


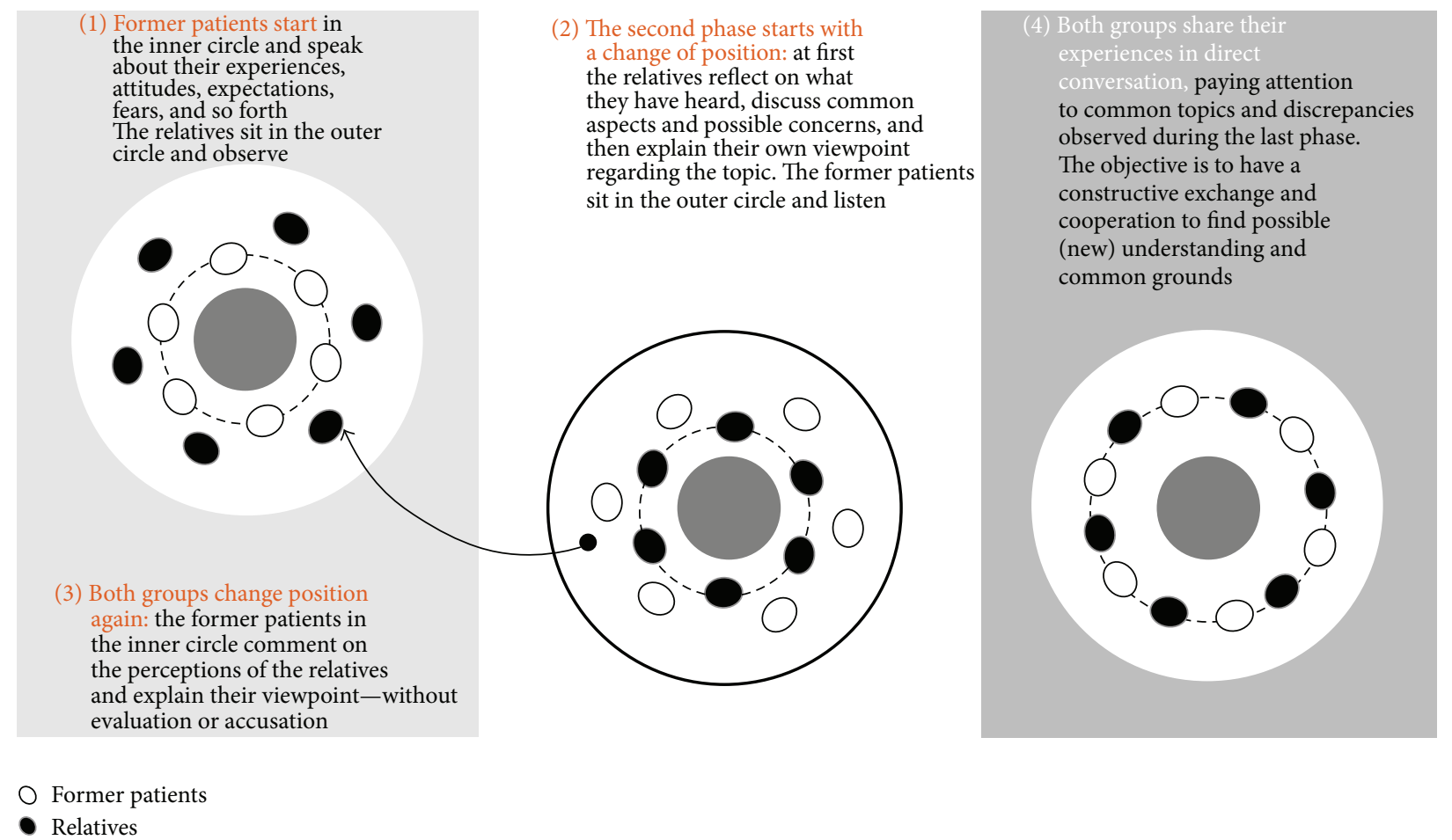

FIgURE 1: Outline of the T-group process used in the qualitative survey.

address the personal history of the participants' relationships satisfactorily. Additionally, when designing this approach for this project, we decided to include former patients and not current patients who would still be suffering and could find the interview setting uncomfortable. Each individual could state their perception so that similarities, differences, and contradictions were observed. The mutual exchange of perspectives, first in the subgroups and then in the whole group, moderated by a psychologist can make it possible to talk about even very sensitive topics. Combining the indepth interviews with a group setting enabled us to obtain an overall assessment of the situation, which in our case was an understanding of the patient-family interaction and the societal impact of $\mathrm{HZ}$ and PHN.

The way the discussions are structured and moderated is important for the success of this approach. For much of the session, the two groups were questioned separately (Figure 1). This enabled the former patients to express themselves first without being influenced by the family members, while the family members were encouraged to listen and understand. After this, the entire group discussed what they had learnt and understood. The group of family members could then talk about their perceptions in a "protected" setting while the former patients were asked to listen and to take notes without interrupting the family members. To help the group to focus on either one subgroup or the entire group, we physically separated or mixed them. There were no tables in the room and the participants sat on chairs arranged in two circles. If the questions were targeted at a subgroup, the other moved to the outer-circle (Figure 1) and if the whole group was involved the members of the subgroups were mixed. One of the moderators always stayed with one of the subgroups.
The T-Group interviews were conducted with five former patients (one had had HZ and four had had PHN) and five former-patients' family members (unrelated to the former patients in the group). The "family members" were either life partners or children who lived close to former patients. The interviews lasted 240 minutes in a studio setting in Berlin, Germany, with video recording for later analysis. The areas covered during these interviews were as follows:

(i) with former patients: their general perception of $\mathrm{HZ}$ or PHN and how they lived with the disease;

(ii) with family members: their experience of the disease with the former $\mathrm{HZ}$ or PHN patients and how they lived with them during the illness;

(iii) with former patients: detailed assessment of the individual stages of the disease;

(iv) with family members: reactions to the detailed assessment of individual stages, with the main objective of encouraging a direct exchange of perspectives about their situation, their understanding of the underlying emotions, the impact the disease had on their daily lives, and any changes in their QoL.

\subsection{Quantitative Phase}

2.2.1. Study Design for Telephone Survey. The telephone survey was undertaken using the in-house telephone studio of GfK Healthcare (who performed the survey). The interviewers were native-German speakers with extensive experience in healthcare surveys. The survey, which was carried out between October 14, 2009, and November 16, 2009, involved 
a 20-minute interview with specifically designed questions that covered various dimensions as follows.

Overall dimensions explored during the 20-minute telephone interview with former patients who had had herpes zoster or postherpetic neuralgia and family members of former patients the following:

(1) impact on social, psychological, health, and financial aspects:

(i) perceived quality of life,

(ii) daily living activities,

(iii) family life,

(iv) relationship with life partner,

(v) social life (seeing friends and doing hobbies and leisure activities),

(vi) psychological life (stress, fatigue, insomnia, and psychological impairment),

(vii) health status (depression or anxiety, weight loss, and use of medication),

(viii) financial impact;

(2) impact on professional life:

(i) time off work or change to flexible working hours (for relatives),

(ii) length of absence from work (for former patients).

The former patients were recruited via their physician and were representative of the German population aged over 50 years in terms of the region where they lived and their household income.

The sample was composed of 168 former patients (HZ: $n=$ 114; PHN: $n=54$ ) who had consulted their physician for their disease and who had had associated pain and 162 family members (life partners: $n=95$; children: $n=67$ ) (Table 1). To be eligible, the former patients had to have been $\geq 50$ years old when they suffered from $\mathrm{HZ}$ ( $<3$ months of pain) or PHN ( $\geq 3$ months of pain) in the five years prior to the survey. The children of the former patients, who had to live near them, were mostly aged 20-49 years. The life partners of the former patients were mostly aged $\geq 50$ years.

\section{Results}

3.1. Qualitative Study Results. The results showed that $\mathrm{HZ}$ and PHN generally have a high impact on the lives of both the former patients and the family members. The majority of the former patients and family members perceived the disease as an important, crucial event in their lives. The former patients' main impressions about the disease were the pain and feeling physically "knocked out." There were strong feelings of helplessness and frustration mixed with depression, sadness, or rage for both the former patients and the family members. Many of the former patients said their lives came to virtual standstill in terms of daily activities, hobbies, leisure activities, and social life; they expressed a feeling of "deadlock." This was in contrast with the family members who said that their lives became very busy and sometimes stressful. There
TABLE 1: Characteristics of the participants in the quantitative telephone survey.

(a) Former patients with herpes zoster or postherpetic neuralgia

\begin{tabular}{lccc}
\hline Characteristic & $\begin{array}{c}\text { Herpes zoster } \\
(n=114)\end{array}$ & $\begin{array}{c}\text { Postherpetic neuralgia } \\
(n=54)\end{array}$ & $\begin{array}{c}\text { Overall } \\
(n=168)\end{array}$ \\
\hline Male/females $(n)$ & $26 / 88$ & $18 / 36$ & $44 / 124$ \\
Mean age (years) & 62.5 & 64.2 & 63.0 \\
Age group $(n)$ & & & \\
50-59 years & 56 & 21 & 77 \\
$\geq 60$ years & 58 & 33 & 91 \\
\hline
\end{tabular}

(b) Family members of former patients with herpes zoster or postherpetic neuralgia

\begin{tabular}{lccc}
\hline & $\begin{array}{c}\text { Life partner } \\
(n=95)\end{array}$ & $\begin{array}{c}\text { Child } \\
(n=67)\end{array}$ & $\begin{array}{c}\text { Overall } \\
(n=162)\end{array}$ \\
\hline $\begin{array}{l}\text { Male/female }(n) \\
\text { Age group }(n)\end{array}$ & $53 / 42$ & $14 / 53$ & $67 / 95$ \\
$\quad$ 20-49 years & 4 & 52 & 56 \\
$\quad \geq 50$ years & 91 & 15 & 106 \\
Related to former patient & & & \\
$\quad$ Herpes zoster & 61 & 48 & 109 \\
$\quad$ Postherpetic neuralgia & 34 & 19 & 53 \\
\hline
\end{tabular}

seemed to be a relatively low impact on the professional lives of the former patients who were working while they were sick (mainly sick leave); the impact on the professional lives of family members was also relatively low, with only a few taking holiday leave or changing working hours. The main societal burden of $\mathrm{HZ}$ and PHN seemed to be human rather than economic and the reported costs incurred were predominantly personal nonmonetary costs. The new role for the "carers" and the former patients' behavioural changes were reported to be sources of stress in their relationships. The former patients and relatives were worried and feared the torment, obsession, and distress caused by the additional burden on their relationships.

Generally, awareness about HZ and PHN was low, although some patients and relatives knew something about the disease aetiology. They said that they knew that triggers such as stress, psychological factors, or a weak immune system could reactivate the chickenpox virus "from childhood" that was "encapsulated" in the body and this reactivation could cause rash and pain. Most of the participants were unsure if the disease was contagious and what the chances of reoccurrence were. They reported a change of attitude towards the disease over time (a before-after phenomenon); usually before, HZ and PHN were considered as "harmless," whereas after they were considered as "severe or very severe."

Following this analysis, we identified the following statements which we used to develop a hypothesis that was verified in the second, quantitative part of the study:

(i) HZ and PHN are perceived as a sign of ageing, "becoming really old";

(ii) $\mathrm{HZ}$ and PHN are part of the comorbidities associated with ageing, a sign of decreasing immunity; 
TABLE 2: Perceived importance of the different areas of support by the carers (life partner or child) and former HZ and PHN patients. The data for the former patients is given as a function of who cared for them, either life-partner or child. The data are the percentages of participants who said the area of support was important.

\begin{tabular}{|c|c|c|c|c|c|c|}
\hline \multicolumn{7}{|c|}{ Question asked: What does your carer (life partner or child) do for you? } \\
\hline \multirow{2}{*}{ Area of support } & \multirow{2}{*}{ Life-partners } & \multirow{2}{*}{ Children } & \multicolumn{2}{|c|}{ Former HZ patients } & \multicolumn{2}{|c|}{ Former PHN patients } \\
\hline & & & Life-partners & Children & Life-partners & Children \\
\hline Shopping & 83 & 84 & 86 & 81 & 71 & 40 \\
\hline Housework & 80 & 75 & 70 & 66 & 74 & 60 \\
\hline Visiting physician & 66 & 63 & 64 & 66 & 68 & 27 \\
\hline Psychological/emotional support & 47 & 36 & 55 & 56 & 77 & 80 \\
\hline Basic activities & 34 & 28 & 39 & 25 & 47 & 27 \\
\hline Washing/showering & 27 & 30 & 20 & 28 & 35 & 20 \\
\hline
\end{tabular}

(iii) families and friends volunteer to help and help to keep the moral up;

(iv) the longer the condition lasts the harder it is for patients and families and friends to cope.

3.2. Quantitative Study Results. Many former HZ/PHN patients were unable to leave their house or even get up from their sofa. More than $85 \%$ of patients with HZ/PHN said that the disease had a moderate to high impact on their daily life and more than $60 \%$ of them said the disease had a moderate to high impact on their family life. In addition, about $40 \%$ of them said there was a moderate to high impact on their professional life and their relationship with their partner.

The majority of the former patients $(\mathrm{HZ}=70 \%$; $\mathrm{PHN}=$ $76 \%$ ) had to have a carer who was most frequently a lifepartner (50\%) and/or a child (30\%), followed by a friend or neighbour. Only very few patients had professional, paid carers. The majority of life partners had cared for the former patient alone, whereas the majority of the former patients' children had support from their other parent, their own life partner, or their own children. The family members of former $\mathrm{HZ}$ patients said they had to give support for about one month, compared with three to four months for those of former PHN patients. They said the main areas of support were doing shopping and housework and visiting physicians with the former patient, followed by psychological and emotional support (Table 2). The former PHN patients assessed the psychological and emotional support as being the most important (Table 2).

The majority of family members (69\% children; $80 \%$ life partners) of patients with $\mathrm{HZ}$ or PHN said that caring for the patient resulted in a moderate to severe impact on their life. Most of them said that the patient's disease had caused them to suffer daily or several times a week from fatigue (life partners: 73\%; children: 62\%), stress (life partners: 66\%; children: 68\%), insomnia (life partners: $57 \%$ ), and emotional distress (life partners: $56 \%$; children: $62 \%$ ). The family members of former PHN patients $(>60 \%)$ said they felt significantly more psychologically impaired than those of former HZ patients did. The most negative aspect of the family members' self-assessed QoL was lack of time; $2 / 3$ said they felt moderately to highly affected by having less time for going out with friends, leisure activities, and their own family.
Family members mainly took vacation or organised flexible working hours to care for the former patient. Life partners had to miss work or change to flexible working hours more often than children ( $42 \%$ versus $20 \%$ ) to care for the former patient. The family members took time off work most often to attend healthcare visits with the former patient. The range of time was from an average of 15 times for part of a day, up to an average of seven whole days. About $40 \%$ said they had suffered from high mental pressure and stress at work due to taking time off work.

The former patients underestimated the psychological and social impacts of their illness on their life partner's or child's health and professional lives. Although more than $60 \%$ of the patients with $\mathrm{HZ}$ or PHN said that their disease had a moderate to high impact on their family life, their evaluation of the impact was lower than that of the family members' selfassessment (Table 3). In addition, the impact of the disease on the normal life of life partners and children was greater for those caring for patients with PHN than those caring for patients with HZ.

Children of patients with PHN reported significantly more depression than that assessed by the former patients (34\% versus 16\%). Children of patients with PHN and life partners of both patients with $\mathrm{HZ}$ and those with PHN reported a significantly higher impact of emotional distress, stress and fatigue, and insomnia than children of patients with HZ. Partners and relatives of patients with PHN (>60\%) felt significantly more psychologically impaired than children or relatives of patients with $\mathrm{HZ}$ ( $63 \%$ versus $53 \% ; P=0.05$ ).

\section{Discussion}

Many studies have assessed the impact of HZ/PHN on the patients' lives but, to our knowledge, this is the first study to assess the impact on those who care for these patients, as well as the patients $[6-10,12,18,19]$. Our results show that an important impact of $\mathrm{HZ}$ and PHN on the lives of patients and their family members (life partners and children) is hidden. In addition, the patients themselves seem to underestimate this impact on the life partners and children.

In the qualitative study, we observed that knowledge about the aetiology of $\mathrm{HZ}$ and $\mathrm{PHN}$ was poor and that the disease was perceived as mild, prior to having direct (former patients) or indirect (family members) experience of the disease. The perception that $\mathrm{HZ}$ was a mild disease by those 
TABLE 3: Percentage of respondents who replied $\geq 4$ (on a scale of 0 (none) to 10 (high)) to questions about the impact of the disease on the different aspects indicated. The former patients gave their assessment of the impact for their carer; the carers gave their self-assessment.

\begin{tabular}{|c|c|c|c|c|c|c|c|}
\hline \multicolumn{8}{|c|}{$\begin{array}{l}\text { Question asked: Caring for or supporting another person that is ill may have an impact on your own health. On a scale from } 1 \text { to } 10,1 \text { meaning } \\
\text { "does not apply at all" and } 10 \text { meaning "applies fully", tell me to what extent the following areas were impacted when took care of or were } \\
\text { supporting your (life-time partner/parent) during their shingles. }\end{array}$} \\
\hline & Fatigue & Weight loss & Insomnia & Emotional distress & Psychological impairment & Depression/anxiety & Stress \\
\hline \multicolumn{8}{|c|}{ Patients assessment for their carer } \\
\hline HZ patients & 38 & 12 & 27 & 47 & 31 & 19 & 53 \\
\hline PHN patients & 36 & 4 & 27 & 39 & 29 & 16 & 39 \\
\hline \multicolumn{8}{|c|}{ Self-assessment by the carer } \\
\hline Life partners & 63 & 14 & 46 & 66 & 51 & 30 & 64 \\
\hline Children & 45 & 13 & 30 & 49 & 34 & 21 & 60 \\
\hline Relatives of HZ patients & 52 & 14 & 35 & 54 & 41 & 22 & 59 \\
\hline Relatives of PHN patients & 60 & 13 & 49 & 70 & 49 & 39 & 70 \\
\hline
\end{tabular}

who were not affected was also reported in a study in Spain on patients with and without $\mathrm{HZ}$ and healthy individuals [13].

One of the advantages of our study was that in the first part we used two different methodologies to obtain our qualitative results, which were confirmed in the second part with a quantitative approach, with a larger sample. Also, this study is the first to assess the impact of $\mathrm{HZ}$ and $\mathrm{PHN}$ on both former patients and family members involved in the care of these patients, in the same study. This approach, which is new in social research, has allowed us to develop a broader picture by combining both internal (patient) and external (family members/carers) experiences.

One of the limitations of our study was the relatively small sample size in the qualitative survey. Although small sample sizes are generally acceptable for this type of methodology, larger-scale studies are needed to evaluate if the results can be extrapolated. Our inclusion criteria required that patients had to have $\mathrm{HZ}$ with pain and while almost $90 \%$ of patients have pain, the remainder do not [20-25]. This inclusion criterion could have led to the selection of patients with a more severe disease. In addition, although the qualitative phase of the study was performed in three towns, they were all located in Germany; therefore, the study should be repeated in other countries to confirm the results.

A live-attenuated VZV vaccine (Zostavax) has been developed with the objective of reducing the incidence and severity of $\mathrm{HZ}$ and its complications, particularly $\mathrm{PHN}$, in adults aged 50 years and more. This vaccine is a paradigm shift in infectious disease management as it is the first licensed vaccine to prevent disease in patients already infected with the pathogen (VZV). By boosting the VZV-specific cellular immunity, the vaccine controls both reactivation and replication of the latent virus to reduce the burden of disease. Its clinical efficacy has been assessed in two pivotal placebo-controlled, double-blind clinical trials, the Shingles Prevention Study (SPS) and ZEST [26, 27]. Its efficacy was assessed in terms of reducing the burden of illness (BOI), that is, the incidence, severity, and duration of HZ-related pain and discomfort, the incidence of $\mathrm{HZ}$, and the incidence of PHN. A reduction of $66 \%$ in the interference with activities of daily living was also reported [28]. Its clinical benefit and good safety profile have also been confirmed in real life conditions [29-32].

The VZV vaccine (Zostavax) was recommended in individuals aged $\geq 60$ years in the US and Canada in 2007 and 2010, respectively. This vaccine was licensed in Europe since 2006 and some European countries, including the UK, Austria, Saxony (Germany), and Sweden, have recently decided to recommend and/or fund this vaccination. Our results suggest that the general public's knowledge about the disease and its consequences could have an important role for the acceptance of the vaccine and therefore the success of a vaccination programme. The study participants suggested that it would be difficult to be interested in the vaccine before the disease occurred, since the disease is perceived as mild, and when the disease occurs and perceptions change, it is too late to vaccinate. It is possible that an educational programme is needed to inform the general public about the disease and its consequences and about the benefits of vaccination. Previous studies have shown that the general public rely on their general practitioner for information and advice about vaccines, particularly new vaccines [33-35]. General practitioners and other health professionals involved in the care of adults $\geq 50$ years could play a central role in patient education and therefore in the success of $\mathrm{HZ}$ vaccination.

\section{Conclusions}

In this study, we showed that $\mathrm{HZ}$ and $\mathrm{PHN}$ had a significant impact, not only on the lives of patients, but also on the lives of the family members who cared for them during the illness. The life partners and children of former patients who had PHN felt more psychologically impaired than those of patients who had HZ. Experience of $\mathrm{HZ}$ or PHN, either as a patient or as someone caring for a patient, changed the perception of the nature of the disease, particularly its severity. Former patients and their family never forget this condition and its considerable impact on their lives, particularly if PHN occurs. The patients themselves generally underestimated the impact of their disease on their life partners and children who cared for them. We need to raise general public awareness about $\mathrm{HZ}$ and $\mathrm{PHN}$ and their often 
severe, debilitating consequences and about the potential benefits from vaccination.

\section{Conflict of Interests}

Thomas Weinke has received honoraria and consulting fees from GlaxoSmithKline, Norvatis Vaccines, and Sanofi Pasteur. Andrea Glogger is an employee of GfK Healthcare who performed the study. Isabelle Bertrand and Kati Lukas are employees of Sanofi Pasteur MSD who funded this study and who commercialise a live, attenuated herpes zoster vaccine in Europe.

\section{Acknowledgments}

The authors take full responsibility for the content of this paper. They would like to thank Margaret Haugh (MediCom Consult) for her assistance in preparing the paper. This study and editorial assistance were funded by Sanofi Pasteur MSD.

\section{References}

[1] O. Lungu, P. W. Annunziato, A. Gershon et al., "Reactivated and latent varicella-zoster virus in human dorsal root ganglia," Proceedings of the National Academy of Sciences of the United States of America, vol. 92, no. 24, pp. 10980-10984, 1995.

[2] A. Arvin, "Aging, immunity, and the varicella-zoster virus," The New England Journal of Medicine, vol. 352, no. 22, pp. 22662267, 2005.

[3] K. E. Schmader and R. H. Dworkin, "Natural history and treatment of herpes zoster," The Journal of Pain, vol. 9, no. 1, pp. S3-S9, 2008.

[4] K. Schmader, J. W. Gnann Jr., and C. P. Watson, “The epidemiological, clinical, and pathological rationale for the herpes zoster vaccine," Journal of Infectious Diseases, vol. 197, no. 2, pp. S207S215, 2008.

[5] R. W. Johnson, D. Bouhassira, G. Kassianos, A. Leplège, K. E. Schmader, and T. Weinke, "The impact of herpes zoster and post-herpetic neuralgia on quality-of-life," BMC Medicine, vol. 8, article 37, 2010.

[6] M. Drolet, M. Brisson, K. E. Schmader et al., "The impact of herpes zoster and postherpetic neuralgia on health-related quality of life: a prospective study," CMAJ, vol. 182, no. 16, pp. 1731-1736, 2010.

[7] T. Weinke, A. Edte, S. Schmitt, and K. Lukas, "Impact of herpes zoster and post-herpetic neuralgia on patients' quality of life: a patient-reported outcomes survey," Zeitschrift fur Gesundheitswissenschaften, vol. 18, pp. 367-374, 2010.

[8] D. Bouhassira, O. Chassany, J. Gaillat et al., "Patient perspective on herpes zoster and its complications: an observational prospective study in patients aged over 50 years in general practice," Pain, vol. 153, no. 2, pp. 342-349, 2012.

[9] K. Lukas, A. Edte, and I. Bertrand, "The impact of herpes zoster and post-herpetic neuralgia on quality of life: patient-reported outcomes in six European countries," Journal of Public Health, vol. 20, no. 4, pp. 441-451, 2012.

[10] R. van Seventer, A. Sadosky, M. Lucero, and E. Dukes, "A crosssectional survey of health state impairment and treatment patterns in patients with postherpetic neuralgia," Age and Ageing, vol. 35, no. 2, pp. 132-137, 2006.
[11] P. M. Coplan, K. Schmader, A. Nikas et al., "Development of a measure of the burden of pain due to herpes zoster and postherpetic neuralgia for prevention trials: adaptation of the brief pain inventory," Journal of Pain, vol. 5, no. 6, pp. 344-356, 2004.

[12] C. Chidiac, J. Bruxelle, J.-P. Daures et al., "Characteristics of patients with herpes zoster on presentation to practitioners in France," Clinical Infectious Diseases, vol. 33, no. 1, pp. 62-69, 2001.

[13] M. J. Álvarez-Pasquín, M. L. Morató, A. Sampedro, M. SanMartín, and Grupo EPIZOSTER, "Perception of herpes zoster in the general population," Vacunas, vol. 12, no. 3, pp. 86-94, 2011.

[14] J. Knodel, "The design and analysis of focus group studies: a practical approach," in Successful Focus Groups: Advancing the State of the Art, D. L. Morgan, Ed., pp. 35-50, Sage, Newbury Park, Calif, USA, 1993.

[15] J. T. Salvendy, "Selection and preparation of patients and organization of the group," in Comprehensive Group Psychotherapy, $\mathrm{H}$. I. Kaplan and B. J. Sadock, Eds., pp. 72-84, William \& Wilkins, Baltimore, Md, USA, 3rd edition, 1993.

[16] D. S. Whitaker and M. D. Lieberman, Psychotherapy through the Group Process, Atherton Press, New York, NY, USA, 1964.

[17] I. D. Yalom, The Theory and Practice of Group Psychotherapy, Basic Books, New York, NY, USA, 3rd edition, 1985.

[18] J. Katz, E. M. Cooper, R. R. Walther, E. W. Sweeney, and R. H. Dworkin, "Acute pain in herpes zoster and its impact on healthrelated quality of life," Clinical Infectious Diseases, vol. 39, no. 3, pp. 342-348, 2004.

[19] K. E. Schmader, R. Sloane, C. Pieper et al., "The impact of acute herpes zoster pain and discomfort on functional status and quality of life in older adults," Clinical Journal of Pain, vol. 23, no. 6, pp. 490-496, 2007.

[20] J. V. Chua and W. H. Chen, "Herpes zoster vaccine for the elderly: boosting immunity," Aging Health, vol. 6, no. 2, pp. 169176, 2010.

[21] R. H. Dworkin, R. W. Johnson, J. Breuer et al., "Recommendations for the management of herpes zoster," Clinical Infectious Diseases, vol. 44, supplement 1, pp. S1-S26, 2007.

[22] J. W. Gnann Jr. and R. J. Whitley, "Herpes zoster," The New England Journal of Medicine, vol. 347, no. 5, pp. 340-346, 2002.

[23] R. W. Johnson, "Zoster-associated pain: what is known, who is at risk and how can it be managed?" Herpes, vol. 14, no. 2, pp. 30-34, 2007.

[24] R. W. Johnson, G. Wasner, P. Saddier, and R. Baron, "Postherpetic neuralgia: epidemiology, pathophysiology and management," Expert Review of Neurotherapeutics, vol. 7, no. 11, pp. 1581-1595, 2007.

[25] R. G. Kost and S. E. Straus, "Postherpetic neuralgia-pathogenesis, treatment, and prevention," The New England Journal of Medicine, vol. 335, no. 1, pp. 32-42, 1996.

[26] M. N. Oxman, M. J. Levin, G. R. Johnson et al., "A vaccine to prevent herpes zoster and postherpetic neuralgia in older adults," The New England Journal of Medicine, vol. 352, no. 22, pp. 2271-2365, 2005.

[27] K. E. Schmader, M. N. Oxman, M. J. Levin et al., "Persistence of the efficacy of zoster vaccine in the shingles prevention study and the short-term persistence substudy," Clinical Infectious Diseases, vol. 55, no. 10, pp. 1320-1328, 2012. 
[28] K. E. Schmader, G. R. Johnson, P. Saddier et al., "Effect of a zoster vaccine on herpes zoster-related interference with functional status and health-related quality-of-life measures in older adults," Journal of the American Geriatrics Society, vol. 58, no. 9, pp. 1634-1641, 2010.

[29] S. M. Langan, L. Smeeth, D. J. Margolis, and S. L. Thomas, "Herpes zoster vaccine effectiveness against incident herpes zoster and post-herpetic neuralgia in an older US population: a cohort study," PLoS Medicine, vol. 10, no. 4, Article ID e1001420, 2013.

[30] H. F. Tseng, A. Liu, L. Sy et al., "Safety of zoster vaccine in adults from a large managed-care cohort: a Vaccine Safety Datalink study," Journal of Internal Medicine, vol. 271, no. 5, pp. 510-520, 2012.

[31] H. F. Tseng, N. Smith, R. Harpaz, S. R. Bialek, L. S. Sy, and S. J. Jacobsen, "Herpes zoster vaccine in older adults and the risk of subsequent herpes zoster disease," The Journal of the American Medical Association, vol. 305, no. 2, pp. 160-166, 2011.

[32] J. Zhang, F. Xie, E. Delzell et al., "Association between vaccination for herpes zoster and risk of herpes zoster infection among older patients with selected immune-mediated diseases," The Journal of the American Medical Association, vol. 308, no. 1, pp. 43-49, 2012.

[33] G. L. Freed, S. J. Clark, A. T. Butchart, D. C. Singer, and M. M. Davis, "Sources and perceived credibility of vaccine-safety information for parents," Pediatrics, vol. 127, supplement 1, pp. S107-S112, 2011.

[34] J. Hughes, J. R. Cates, N. Liddon, J. S. Smith, S. L. Gottlieb, and N. T. Brewer, "Disparities in how parents are learning about the human papillomavirus vaccine," Cancer Epidemiology Biomarkers and Prevention, vol. 18, no. 2, pp. 363-372, 2009.

[35] A. Kennedy, M. Basket, and K. Sheedy, "Vaccine attitudes, concerns, and information sources reported by parents of young children: results from the 2009 HealthStyles survey," Pediatrics, vol. 127, no. 1, pp. S92-S99, 2011. 


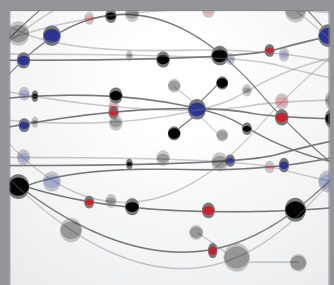

The Scientific World Journal
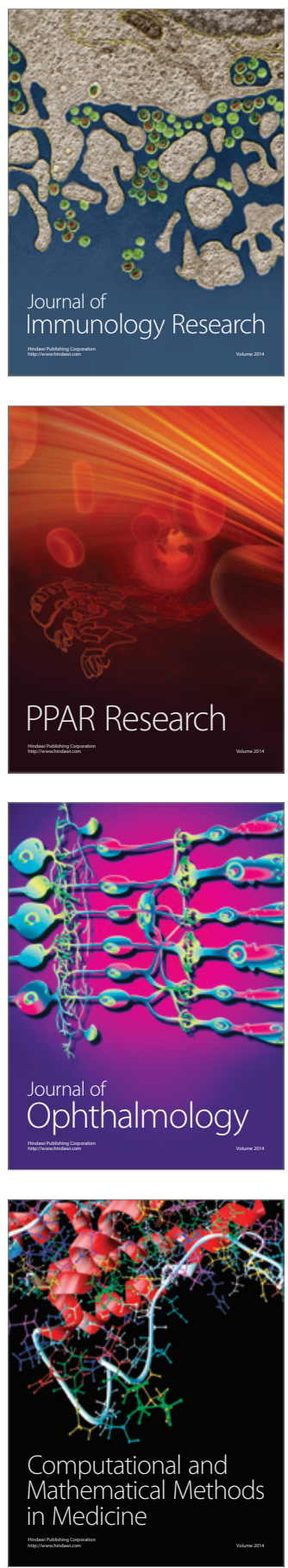

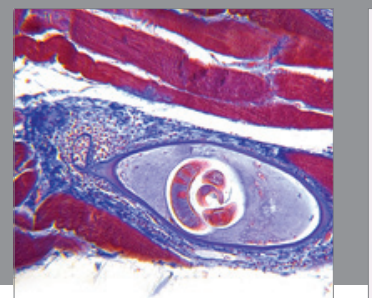

Gastroenterology

Research and Practice
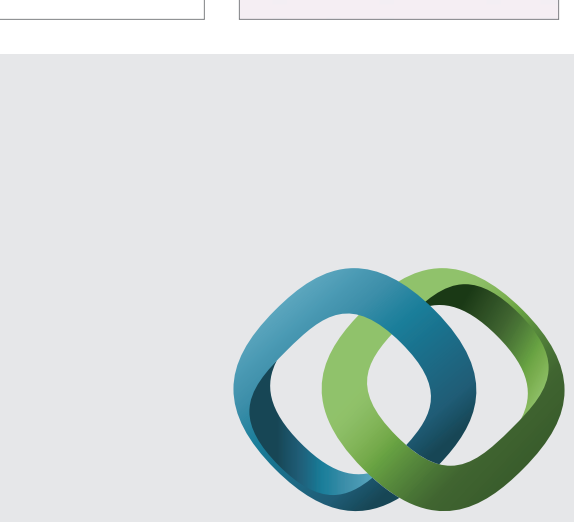

\section{Hindawi}

Submit your manuscripts at

http://www.hindawi.com
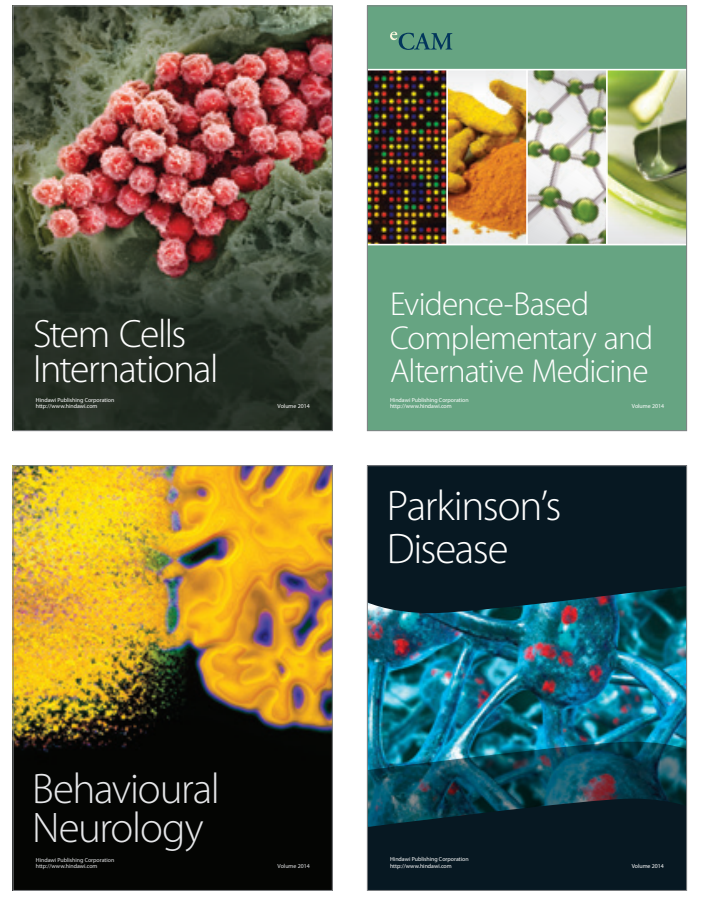
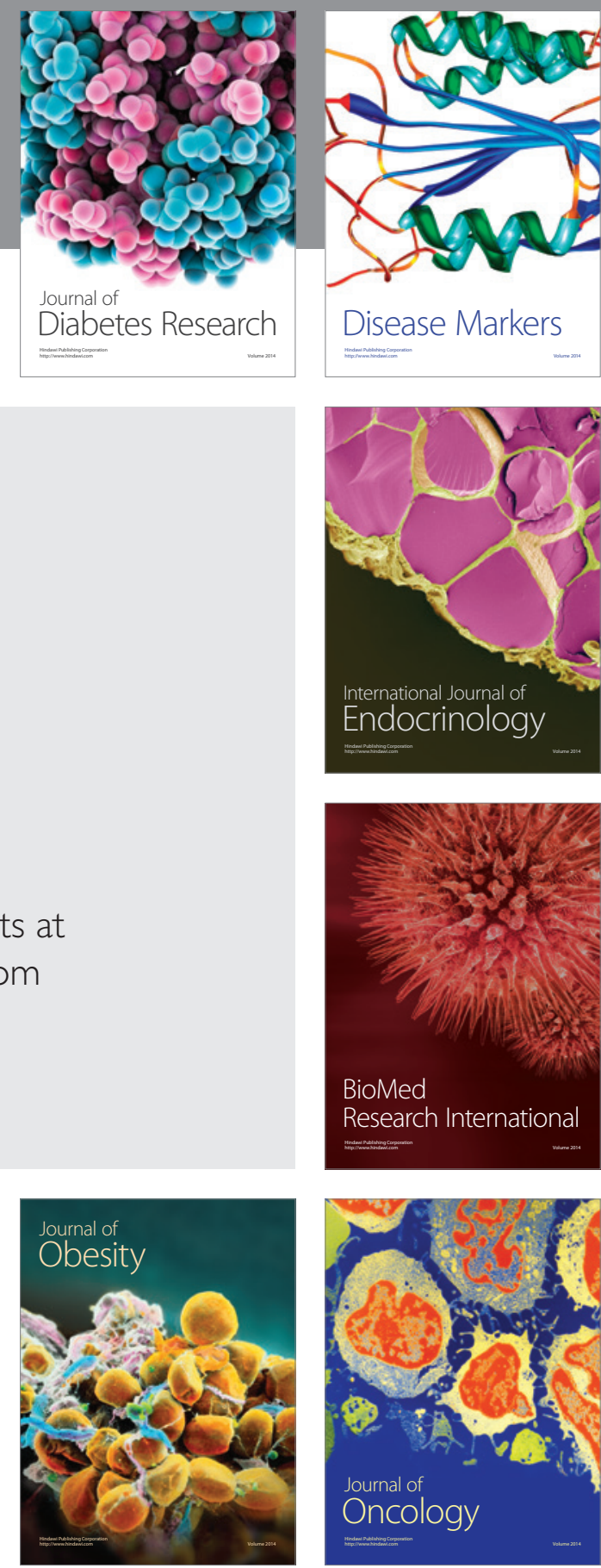

Disease Markers
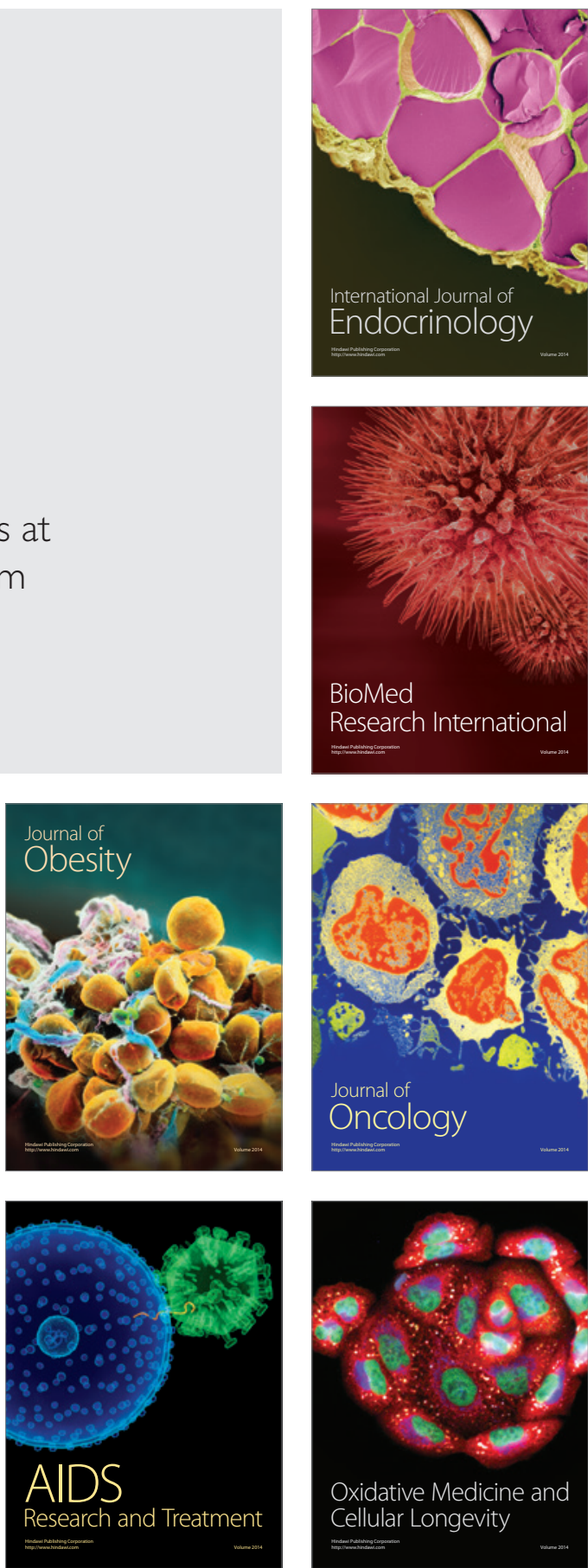